\title{
Infected esophageal subepithelial hematoma after peroral endoscopic myotomy for achalasia successfully treated with double-pigtail stent drainage
}

Peroral endoscopic myotomy (POEM) has proven similarly effective to and less invasive than laparoscopic Heller myotomy and become the preferred option for the treatment of esophageal achalasia [1]. Few post-operative adverse events have been reported, among them a very low incidence of delayed bleeding causing a submucosal hematoma that could be treated with conservative management $[2,3]$.

We report a case of a 47-year-old man who underwent a successful POEM for a type of esophageal achalasia. He was readmitted to our center 10 days later for worsening epigastric pain with fever. A CT scan showed a right-side esophageal subepithelial collection ( $\mathbf{F i g . 1}$ ). An infected submucosal hematoma was diagnosed. Despite initial conservative treatment with a broad-spectrum antibiotic and anti-fungal, the patient continued to be septic. After multidisciplinary discussion, we decided to drain the submucosal abscess endoscopically. During the procedure ( $\vee$ Video 1 ), a small ulcerated orifice with discharged pus was seen on the previous POEM tunnel. We cannulated the submucosal space via this orifice with a guidewire and then placed a 7 French double-pigtail stent under endoscopic ultrasound control and fluoroscopic guidance (- Fig. 2). A significant clinical and biological improvement was achieved, and the patient was discharged home the next day with an oral antibiotic. A 10-day follow-up CT scan revealed complete resolution of the collection with the stent in place, which was planned for removal in 1 month ( $>$ Fig. 3 ). Even though a post-POEM submucosal hematoma is rare and can resolve spontaneously, infection can occur and might require additional management. The feasibility and efficacy of endoscopic transmural drainage of an intra-abdominal collection was already well established [4]. It was also demonstrated to be feasible for a gastric wall abscess after endo-

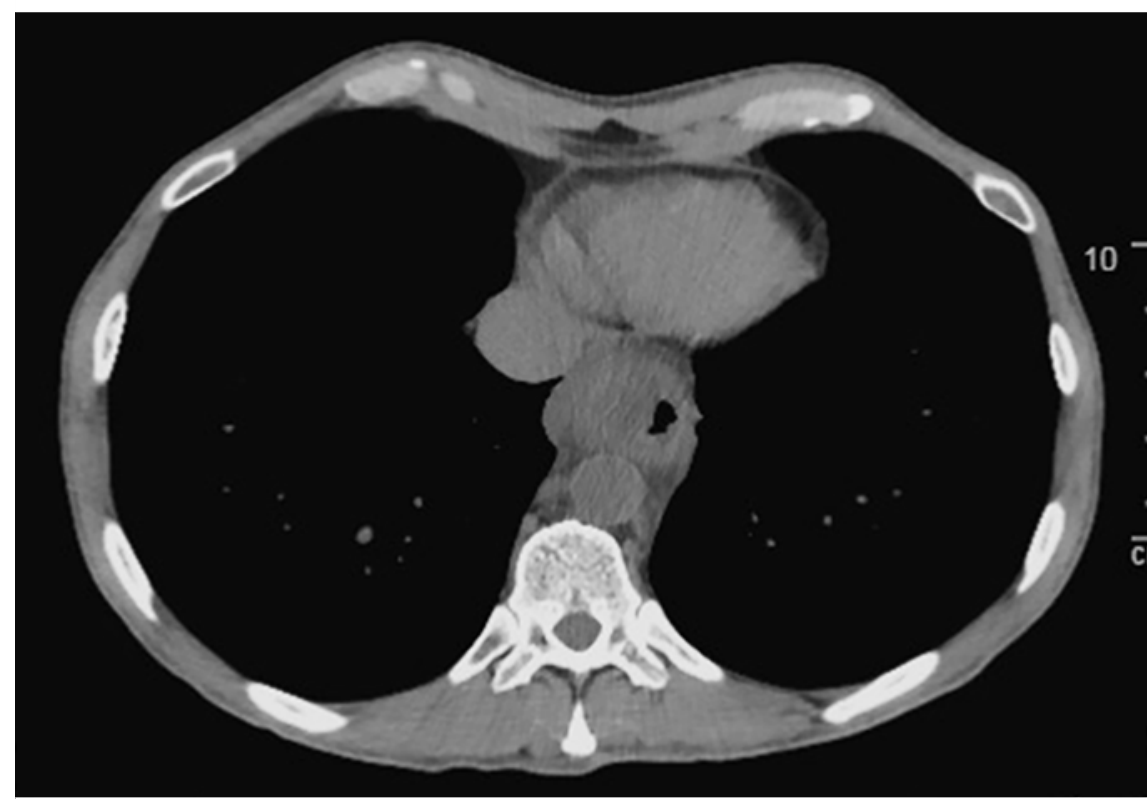

- Fig. 1 CT scan shows a large esophageal tunnel hematoma.

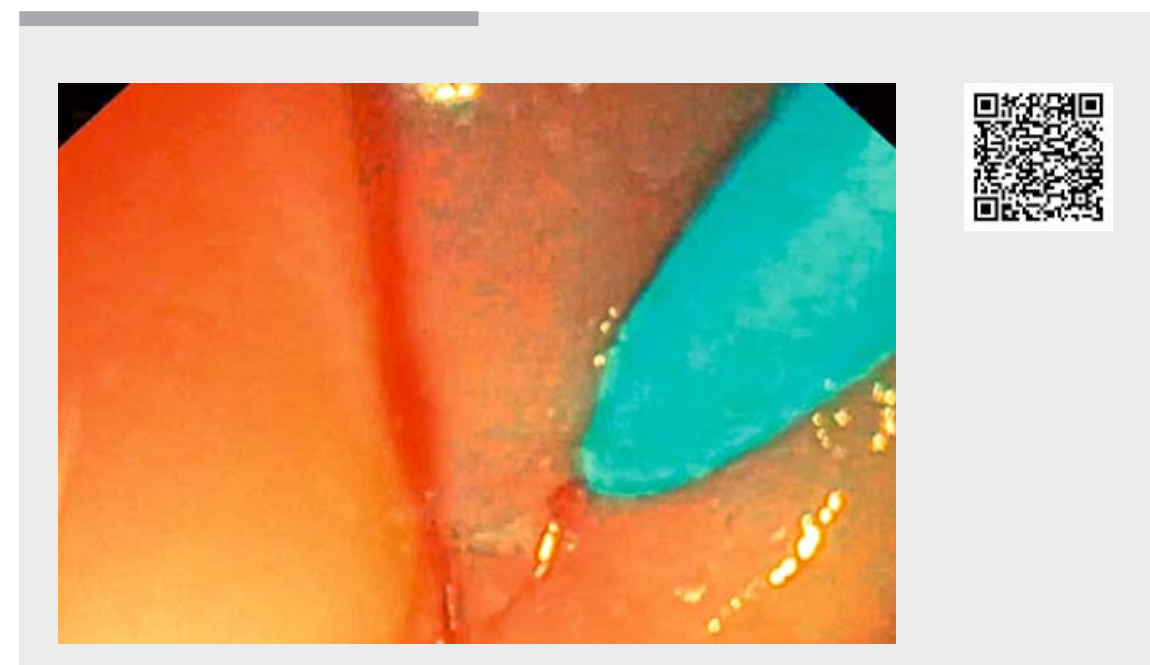

$\nabla$ Video 1 Successful double-pigtail stent drainage of infected esophageal subepithelial hematoma after peroral endoscopic myotomy for achalasia.

scopic submucosal dissection [5]. We beEndoscopy_UCTN_Code_CPL_1AH_2AJ 

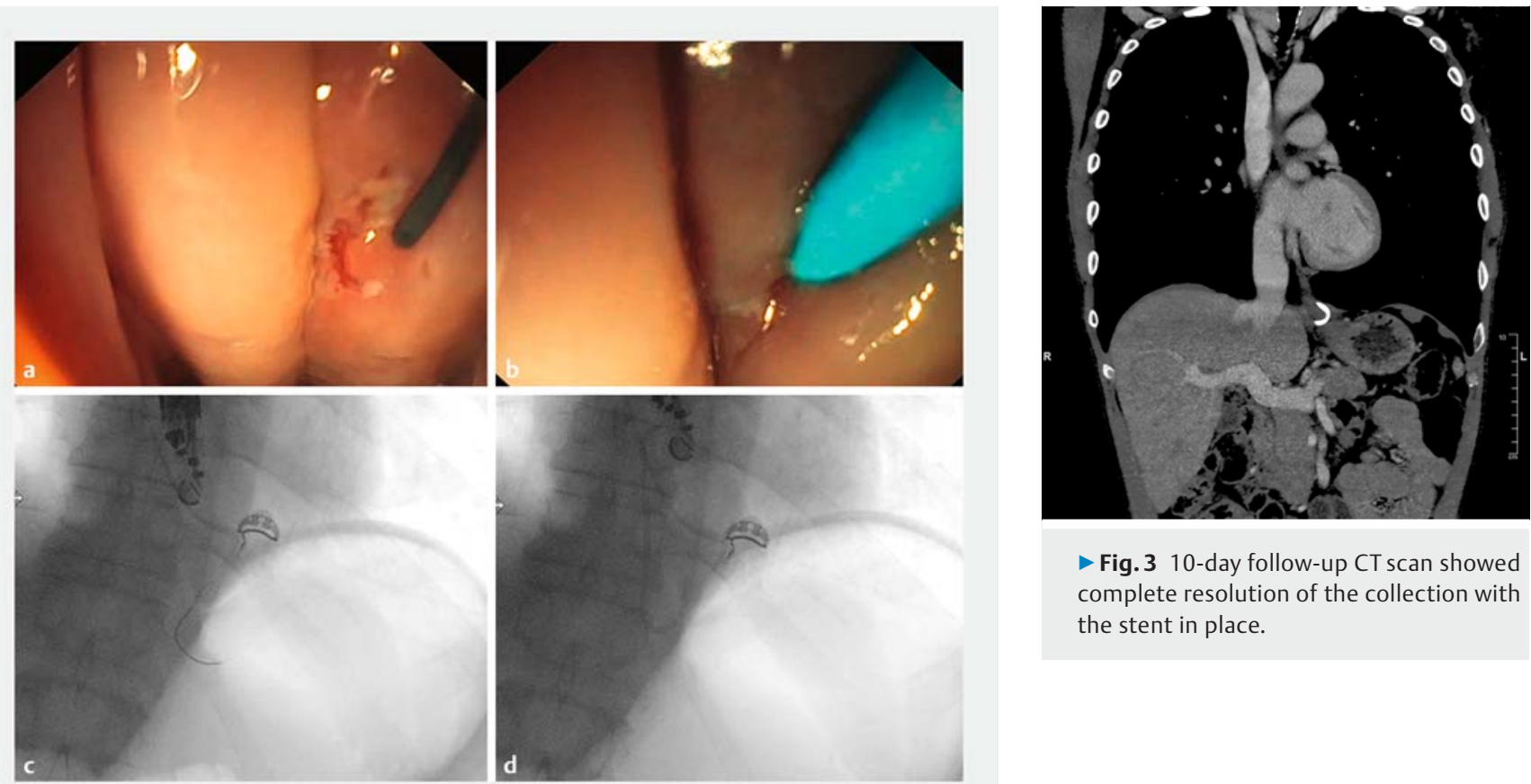

- Fig. 3 10-day follow-up CT scan showed complete resolution of the collection with the stent in place.

- Fig. 2 Endoscopic drainage procedure. a Small ulcerated orifice on the previous POEM tunnel. b Insertion of 7 French double-pigtail stent. c Guidewire placement in the tunnel via the orifice. $\mathbf{d}$ Placement of 7 French double-pigtail stent under fluoroscopic guidance.

\section{Competing interests}

The authors declare that they have no conflict of interest.

The authors

Borathchakra Oung ${ }^{1,2}$, Florian Rostain', Jérôme Rivory', André Boibieux ${ }^{3}$, Armelle Schoch ${ }^{1}$, François Mion ${ }^{4}$, Mathieu Pioche ${ }^{1}$

1 Department of Endoscopy and Gastroenterology, Pavillon L, Edouard Herriot Hospital, Lyon, France

2 Cambodian Association of Gastrointestinal Endoscopy (CAGE), Cambodia

3 Infectious Diseases Unit, Edouard Herriot Hospital, Lyon, France

4 Digestive Physiology Department, Université de Lyon, Lyon, France

\section{Corresponding author}

\section{Dr. Mathieu Pioche}

Endoscopy Unit, Digestive Disease

Department, Pavillon L, Edouard Herriot

Hospital, 69437 Lyon CEDEX, France

Fax: +33472110146

mathieu.pioche@chu-lyon.fr
References

[1] Kahrilas PJ, Katzka D, Richter JE. Clinical practice update: the use of per-oral endoscopic myotomy in achalasia: expert review and best practice advice from the AGA Institute. Gastroenterology 2017; 153: 12051211

[2] Ren Z, Zhong Y, Zhou P et al. Perioperative management and treatment for complications during and after peroral endoscopic myotomy (POEM) for esophageal achalasia (EA) (data from 119 cases). Surg Endosc 2012; 26: 3267-3272

[3] Benech N, Pioche M, O’Brien M et al. Esophageal hematoma after peroral endoscopic myotomy for achalasia in a patient on antiplatelet therapy. Endoscopy 2015; 47: E363-E364

[4] Donatelli G, Fuks D, Cereatti F et al. Endoscopic transmural management of abdominal fluid collection following gastrointestinal, bariatric, and hepato-bilio-pancreatic surgery. Surg Endosc 2018; 32: 2281-2287

[5] Dohi O, Dohi M, Inoue K et al. Endoscopic transgastric drainage of a gastric wall abscess after endoscopic submucosal dissection. World J Gastroenterol 2014; 20: 11191122
DOI https://doi.org/10.1055/a-1085-2579

Published online: 22.1.2020

Endoscopy 2020; 52: E237-E238

(c) Georg Thieme Verlag KG

Stuttgart · New York

ISSN 0013-726X

\section{ENDOSCOPY E-VIDEOS}

https://eref.thieme.de/e-videos

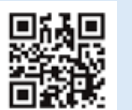

Endoscopy E-Videos is a free access online section, reporting on interesting cases and new techniques in gastroenterological endoscopy. All papers include a high quality video and all contributions are freely accessible online.

This section has its own submission website at

https://mc.manuscriptcentral.com/e-videos 